\title{
comment
}

\section{Freeman on Deduction/Induction}

\author{
George Englebretsen \\ Bishop's University
}

I ask each of my logic students to give me an example of a deductive argument.

Student a offers:

Da) All men are rational.

All U.S. presidents are men.

So. all U.S. presidents must be rational.

Student b offers:

Db) Washington was rational.

Lincoln was rational.

Kennedy was rational.

So, all U.S. presidents must be rational.

And student c offers:

Dc) Washington was rational.

Lincoln was rational.

Kennedy was rational.

So, probably all U.S. presidents are rational.

Now I ask each to give me an inductive argument.

Student a offers:

1a) Washington was rational.

Lincoln was rational.

Kennedy was rational.

So, probably all U.S. presidents are rational.

Student b offers:

ib) All men are rational.

All U.S. presidents are men.

So, probably all U.S. presidents are rational.

And student coffers:

ic) All men are rational.

All U.S. presidents are men.

So, all U.S. presidents must be rational.
How well has each student fared in carrying out my assignment? To answer this I must be able to decide in the case of each argument whether it is deductive or inductive. In [1] James B. Freeman offers this criterion (p. 9, para. 7):

An argument is to be judged deductive (inductive) as the balance of deductive indicators outweighs the balance of inductive indicators the balance of inductive indicators outweighs deductive indicators). In particular, all things being equal, when an argument specifically claims that its premises guarantee the truth of its conclusion or when it belongs to a deductive family, it should be judged deductive. Similarly, when it claims that its premises only give evidence for its conclusion, or when it belongs to an inductive family, it should be judged inductive.

Earlier (p. 9, para. 3) Freeman has suggested that in cases where all things are not equal (viz., when explicit and implicit indicators conflict) we "might" adopt the policy of giving explicit indicators precedence.

So it would seem that among deductive/inductive in dicators are: (i) the claim made by the given argument, and (ii) the membership of the argument in a deductive/inductive family. Furthermore, the claims mentioned in (i) may be explicit (by use of "metalinguistic illation sign modifiers") or implicit. With regard to (ii), Freeman holds that tradition assigns arguments to such families (cf. p. 8, para. 6).

$$
\because
$$

I have no doubts about the deductive/inductive distinction. I do have doubts about Freeman's recipe for applying that distinction. Let's consider the arguments given me by my three students. All the indicators in Da point to deduction. It has a form traditionally assigned to the deductive family; it has an explicit illation sign ("must"), which marks it as a deduction; and we might add, its author's implicit claim (indicated by his sincere submission of the argument to satisfy my re- 
quest for deductions) is that it is deductive. On virtually any criteria student a seems successful here. And he seems equally successful in carrying out my second assignment. All the indicators in la point to induction. It has a form traditionally assigned to the inductive family; it has an explicit illation sign ("probably"), which marks it as an induction; and its author's implicit claim (indicated by his sincere submission of the argument to satisfy my request for inductions) is that it is inductive.

Whein we look at $c$ it would seem his failure is as complete as a's success. Given that c submitted Dc in a sincere attempt to satisfy my request for deductions, I must assume that his implicit claim for the argument is that it is deductive. Yet tradition assigns Dc to the inductive family and its explicit illation sign weighs it inductively. Student $\boldsymbol{c}^{\prime}$ Ic seems a comparable failure. For similar reasons I must assume that $\mathbf{c}$ has implicitly taken Ic as an induction even though all indicators are that it is deductive.

What now of $\mathbf{b}$ ? His implicit claim for $\mathbf{D b}$ must be that it is deductive. And he used an explicit illation sign to support this. But tradition assigns the argument to the inductive family. Likewise with $\mathbf{l b}$. The implicit claim that $\mathbf{l b}$ is inductive is supported by the explicit use of an appropriate illation sign. Yet tradition takes the argument to be deductive. Do I pass student $\mathbf{b}$ along with $\mathbf{a}$, or do I fail him along with $\mathbf{c}$ ? I will pass him if I judge $\mathbf{D b}$ as a deduction and $\mathbf{l b}$ as an induction, otherwise I will fail him. Clearly 1 , and presumably most other teachers of logic, would fail b. We would not take either Db as a deductive argument or $\mathbf{l b}$ as an inductive one. We would ignore the implicit claims for each argument made by the student here. And we would likewise ignore his explicit uses of illation signs. We would judge his arguments solely on the basis of what Freeman calls "tradition". Indeed, our task as logic teachers is to bring b's implicit claims and uses of illative signs into line with this tradition.

Concerning just such cases Freeman's only recourse is either accept tradition, make use of his supplementary policy giving precedence to explicit indictators, or to avoid classification all together by admitting them as recalcitrant "freaks". Freeman has no argument for the second alternative; and the third would in practice not be resorted to by logicians.

So it would seem that in fact our choice is simply adjudication by tradition. But surely this is no criterion at all. For the obvious and immediate question then is: How has tradition been able to make this deduction/induction distinction? Back to square one!

Let me offer a brief suggestion. It seems to me that the formal logician's central concern is with entailment. He holds that whether or not a (possibly singleton or even nuli) set of sentences entails a given sentence (i.e. validity) is determined by the logical forms of those sentences. He requires, therefore, a theory of logical form and a calculus for determining validity. The standard theories and calculi (e.g. syllogistic, first-order predicate) are deductive. The formal logician (qua deductive logician) takes all entailments as purported deductions and judges them accordingly. Some will be deductively valid, some will be deductively invalid. Among those taken to be deductively invalid will be some which nonetheless are such that the purportedly entailing sentence-set at least supports (in varying degrees and ways) the entailed sentence. The logician (now qua inductive logician) formulates a different set of criteria for validity-a set which, unlike the criteria for deductive validity, permits degrees of validity. The formal logician (qua deductive logician) is free of course simply to go on calling these arguments deductively invalid and leave it at that (i.e. he is free not be an inductive logician). Now notice that on this account there is no mention of speakers' claims, illation signs, etc. Sentence-set $\mathbf{S}$ will deductively/inductively entail sentence s or it will not-and this whether or not the producer holds that it does, or even if there is no specifiable pro. ducer, and whether there are any explicit/implicit illation signs or not. Suppose I find a piece of paper with the sentence

1) All men are rational.

written on it. At some other time (earlier or later) I hear on the radio

2) All U.S. presidents are men.

And at some other time still I read on my classroom blackboard

3) All U.S. presidents are rational.

I would be a poor logician not to recognize that 1 and 2 jointly entail 3. There are no explicit or implicit indicators here. There is no specifiable author to claim explicitly or implicitly that and how 1 and 2 relate to 3 . Yet I judge these sentences to constitute a (valid) deductive argument. Had I similarly found these sentences:

3) All U.S. presidents are rational.

4) Washington was rational.

5) Lincoln was rational.

6) Kennedy was rational.

I would, without benefit of authors' claims or illation signs, judge these sentences as constituting (all on their own) and invalid deduction of 3 from 4-6 or an induction of 3 from 4-6.

I want to add one very brief final note on the question of the role of informal logic here. I take it that the informal logician is clearly not doing a third kind of logic on a par with deductive or inductive logic. The informal logician's central concern is not with determining validity for entailments. (It was once suggested to me that where the formal logician determines validity on the basis of form, the informal logician determines it on the basis of matter or content!) What the informal logician is centrally concerned with is apparent validity. $\mathrm{He}$ is interested in accounting for arguments which seem to satisfy criteria for (deductive/inductive) validity which in fact do not. Such arguments are fallacious-and informal logic just is the logic of fallacies (cf. [2]).

\section{Notes}

1 Freeman, J.B., "Logical Form, Probability Interpretations, and the Inductive/Deductive Distinction," Informal Logic Newsletter, v.2 (1983), 2-10.

2 Woods, J. and Walton, D., Argument: The Logic of the Fallacies, Toronto; McGraw-Hill Ryerson, 1982.

George Englebretsen, Department of Philosophy, Bishop's University, Lennoxville, Quebec. 